\title{
FINE TURNING OF THE VEHICLE FORMED COMPONENTS COATED BY THE ULTRA-HARD POLYCRYSTALLINE TOOLS
}

\author{
Klimenko Sergey Anatolievich* \\ Bakul Institute of hard materials of NAN of Ukraine, Kiev \\ Trofimov Igor Leonidovsch \\ Bakul Institute of hard materials of NAN of Ukraine, Kiev \\ Burykin Vitaliy Vitalievich \\ Bakul Institute of hard materials of NAN of Ukraine, Kiev \\ Prymak Liudmyla Borysivna \\ Bakul Institute of hard materials of NAN of Ukraine, Kiev \\ Ljubodrag Tanović \\ University of Belgrade, Faculty of mechanical engineering, Belgrade, Serbia
}

The questions considering cutting treatment of the shaped details with chromium-nickel coatings by lathe instruments, equipped polycrystalline ultra hard materials on the basis of cubic boron nitride of the coniferous forest. The features of technologies of lathe treatment of details are rotined with coverages at the improvement of structural descriptions of cutting plate, technological parameters of process of cutting and coverages on an instrument. It is set that application of sheeting allows to promote firmness of polycrystalline instruments on the stage of earning extra money due to diminishing of adhesive contact between the processed and instrumental materials.

Key words: A disposable insert, Protective coating

\section{INTRODUCTION}

Changing of the primary geometry of products in the process of operation and increased wear of the working surfaces of the parts are among the main reasons for reduction of their operation life, failure of machines and mechanisms. The intensity of the wear of the parts is dependent on the type of machine, its power, operating conditions, material of the parts and methods of protection. In most cases, the repair is economically expedient, as the cost of restoration of the worn parts is not more than $30-40 \%$ of the cost of new ones [01].

An effective method of solving the problem of providing high performance machinery is the application of very hard, heat-resistant and corrosion-resistant coatings on working surfaces of the parts with the use of plasma, electron beam, detonation and other technologies.

Chromium-nickel powders such as ПГ-СР 3, ПГ$\mathrm{CP} 4, \Pi Г-10 \mathrm{H}-01$ have found widespread use in the process of hardening and restoration of the parts of machines [02].
To provide high operational properties of the coated parts as a result of the restoration an urgent task is improving the processes of their processing.

Low machinability of chromium-nickel coatings is a consequence of their high hardness, high ability of abrasiveness of carbide and boride inclusions, high temperatures occurring in the cutting area and other factors. In such circumstances, tool materials must have high hardness and strength in a wide range of temperatures and pressures, sufficient toughness, good thermal conductivity, low tendency of adhesion to the work material and diffusion.

Currently, a great field experience has been accumulated of the use of ultra-hard materials [0305] for machinery of the hard coatings. In the industry the most widely used are the composites K01, K10 and Kiborit made of polycrystalline ultra-hard materials (PCBN), cutting conditions at turning of chromium-nickel coatings are given in Table 1. 
Table 1: Cutting conditions at turning of chromium-nickel coatings

\begin{tabular}{|c|c|c|c|}
\hline \multirow{2}{*}{ Tool material } & \multicolumn{3}{|c|}{ Cutting conditions } \\
\cline { 2 - 4 } & velocity $\mathrm{v}, \mathrm{m} / \mathrm{s}$ & Carrying-in $S, \mathrm{~m} / \mathrm{rev}$ & depth $t, \mathrm{~mm}$ \\
\hline K01 & $1.0-1.2$ & $0.07-0.09$ & $0.3-0.5$ \\
\hline K10 & $1.3-2.0$ & $0.10-0.15$ & $0.3-1.0$ \\
\hline Kiborit & $1.5-2.5$ & $0.10-0.30$ & $0.2-2.0$ \\
\hline
\end{tabular}

The purpose of this work is to improve the working capacity of the cutters with a mechanical fastening of cutting inserts PCBN at fine turning of the formed components fine with hard coatings by improving the designs of the cutting tool and to create protective coatings on the tool.

\section{RESULTS AND DISCUSSIONS}

On the assumption of the fact that the radii of connections of the cross-section curve warped transitions of the machined part is larger than the radius of the insert itself, the cylindrical cutting tool enables to process the formed components, such as bodies of revolution. Strength conditions of the cutting edge of a plate PST require the presence of a cutting angle not less than $90^{\circ}$ and respectively, and at the ends of the plane-parallel insert it is necessary to fix it with a negative front angle. In this case, a sufficient back angle is provided in a very narrow range of divergences of the cutter top position, moving during the process of cutting by the cutting edge of the tool, about $\pm 30^{\circ}$ relatively to the longitudinal axis of the cutter. When processing the ridges or cavities of the profile by the side edges of the inserts the back angle is substantially reduced. When the position of the top of tool at the point on the cutting edge where the radius of the insert drawn from this point which together with the longitudinal axis makes an angle close to perpendicular, rubbing of the cutter occurs.

When processing the complex profile parts a conditional top of the cutter is moving as on forming of the profile as on the cutting edge. In this case it is important to meet the conditions of constancy of the front and back angles of the tool at any point of the surface of rotation forming a complex contour that does not have cutters with a fixed front angle and an angle of inclination of the cutting edge. To fulfill these conditions a special disposable insert made of PCBN has been developed (Figure 1a) [06] and the cutter holder (Figure 2). The symbol $\mathrm{R}$ corresponds this insert $(B, C, P) M H$ depending on the value of the back angle respectively $5^{\circ}, 7^{\circ}$ or $11^{\circ}$. The bearing surface of the cutting insert is a conical surface which is installed in a corresponding conical socket on the cutter holder. By rotating in the socket the insert has four or five periods of efficient life.

Taking into account that the processed products are with hard coatings, the front angle of the cutting insert has a negative value. Therefore, the plate is provided with a reinforcing chamfer at the angle $-10^{\circ}$ and the width $0.15-0.20 \mathrm{~mm}$.

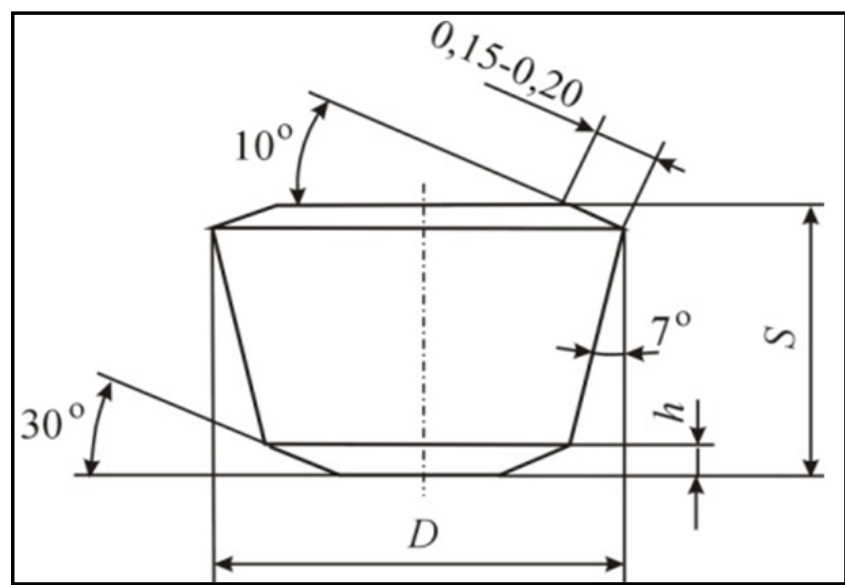

a)

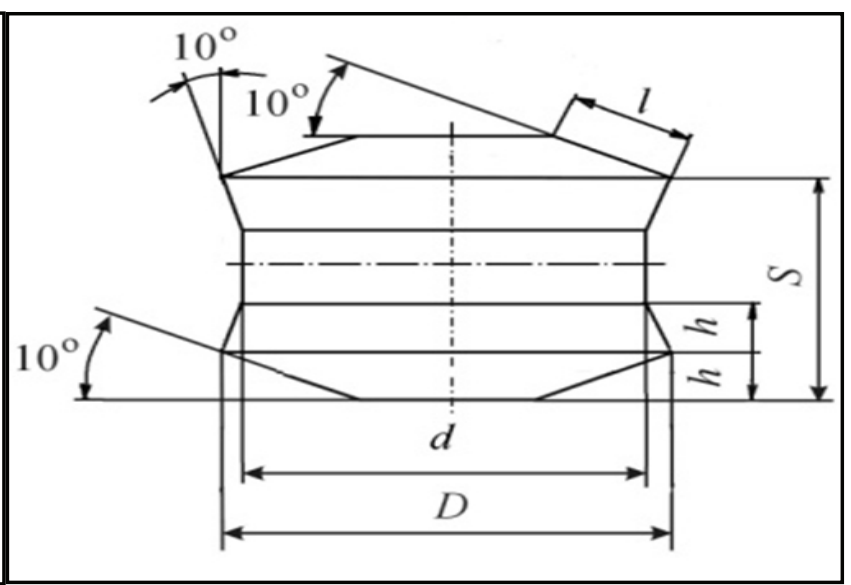

b)

Figure 1: Cutting PCBN insert single-sided (a) and double-sided (b) 
Operating characteristics of the tool with the inserts of the described construction, are to a certain extent limited by the presence of only one cutting edge that allows in case of wear only to reset the insert in the cutter holder by turning it about a vertical axis.

To eliminate this imperfection an axisymmetric round insert with two cutting edges has been developed, as shown in Figure 1b. Such insert can be mounted in the cutter holder in a similar manner, but at the same time, its design allows doubling the cutter efficient life in comparison with a single-sided insert.

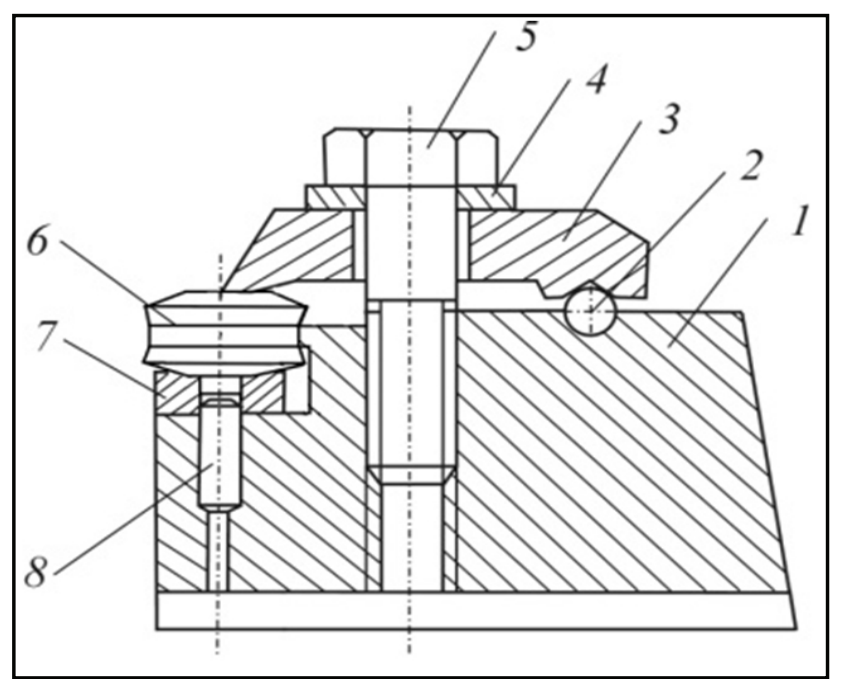

Figure 2: The construction of the cutter holder: 1-body; 2-bearing ball; 3-pressing; 4-washer; 5-screw; 6-cutting insert; 7-separator; 8-pin

In the case of using such inserts the tool has a nonplanar front surface, which significantly affects the chip formation process, changes the angles of a chip flow and deformation conditions in the cutting area. In fact, in this case there is a front surface with a variable front angle, depending on the thickness of the cut and its width. In this connection, in the process of turning the contact areas of the tool will vary.

A mechanical fastening of the cutting insert is performed by a pressing, the tail of which is based on the ball. The cutting insert is mounted into a conical socket of the separator in the holder.

Along with the undoubted advantages of the cutters with cutting inserts of this design, there are some difficulties in manufacturing and in the use of the tool. In the manufacture of the described inserts there are increased requirements for the equipment and grinding tools, as it is necessary to grind toroidal or conical undercuts at the side of the insert. In this case it is necessary to ensure higher accuracy of dressing of the the diamond wheel and axial movements of the insert to get the cutting edge of high quality. When operating the cutters with the developed inserts it is necessary to position the cutter more accurately in height relative to the longitudinal axis of the processed part, in particular - the large diameter, to avoid rubbing of the rear surface of the non-working part of the inserts and the processed part.

Check of the developed tool at the processing with chrome-nickel coatings showed a good performance in operation.

The scientific ideas for obtaining PCBN on the basis of CBN for the edge cutting machining of the parts with coatings are based, first, on the fundamental concepts of obtaining composites with desired physical and mechanical properties, and secondly - on the information about the nature of physical and chemical processes occurring in the tool and the contact area of the processed material. The features of these processes determine the complexity of the tool wear (combination of wear mechanisms: abrasion, adhesion, diffusion, oxidation, chemical wear due to eutectic melting). The service life of the cutters for chromium-nickel coatings is largely limited by a strong tribochemical interaction of the tool material and processing material in the cutting area.

To improve the tool performance the materials must resist the mechanisms of wear caused by abrasion, diffusion and dissolution of the tool material in the processed material. Thus the tool material must be viscous enough to resist chipping and cracking of its cutting edges. Since none of these materials has such properties, then another efficient solution to the problem of increasing the efficiency of the cutting tools is application of various coatings on their work surfaces of [07].

Such coatings significantly reduce cutting forces, change heat-beating of the process, reduce the wear by reducing the connection of the tool with the processed material to prevent diffusion of the atoms in the tool material in the processed and the opposite directions, which in turn improves the tool service life and allows intensifying the cutting process $[08,09]$.

In this research the PCBN inserts were used with the $\mathrm{n}$-TiC/a-C coating (Figure 3). The mechanical characteristics of the coating are given in Table 2. 


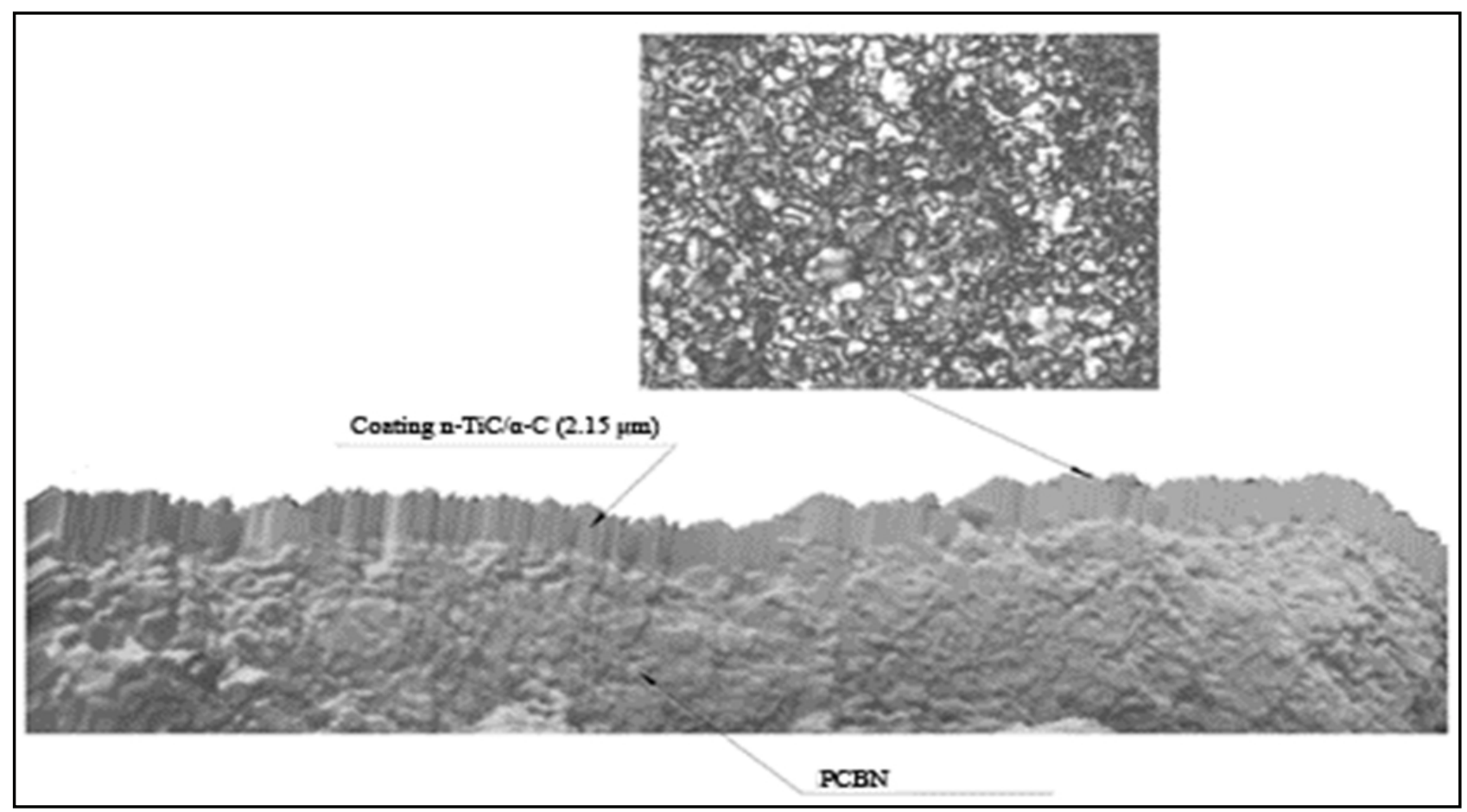

Figure 3: Cross-section of the working area of the tool with the $n-T i C / \alpha-C$ coating

Check of the operating capacity of the cutting tools at fine turning of the restored parts showed that the tool wear with a coated rear surface is by $15-20 \%$ lower than this one with an uncoated tool.

Table 2: Mechanical characteristics of coating

\begin{tabular}{|c|c|c|c|c|}
\hline Coating & $H, G P a$ & $H / E$ & E, GPa & $\varepsilon, \%$ \\
\hline $\begin{array}{c}\mathrm{n}-\mathrm{TiC} / \mathrm{a}-\mathrm{C} \text { TiC } \\
\delta=0.15 \mu \mathrm{m}+ \\
\text { TiC/a-C } \\
\delta=2 \mu \mathrm{m}\end{array}$ & 26 & 0.088 & 296 & 2.694 \\
\hline
\end{tabular}

The coating minimizes the adhesive interaction of the tool with the processed material, and it results in lower tool wear. Tool wear is intensified when the coating on the contact areas is partially removed and the interaction of the processed nickel-chromium coating is carried out directly with the PCBN.

The prevailing mechanism of the PCBN tool wear with coatings at the processing of the restored parts is the abrasion-adhesion mechanism. On the contact areas of the tool (Figure 4a) one can clearly see distinctive cavities of the depth 13-16 $\mu \mathrm{m}$, which coincide with the direction of the cutting speed. As a result of the adhesive interaction some separate composite grains of the instrumental composite are being pulled out, forming cavities (Figure 4b). Subsequently, the slime grains help to intensify the abrasive tool wear.

The research has shown that the greatest effect of the protective coatings is shown on the phase of running-in the tool, which allows increasing the resistance during the unstable loading of the tool.

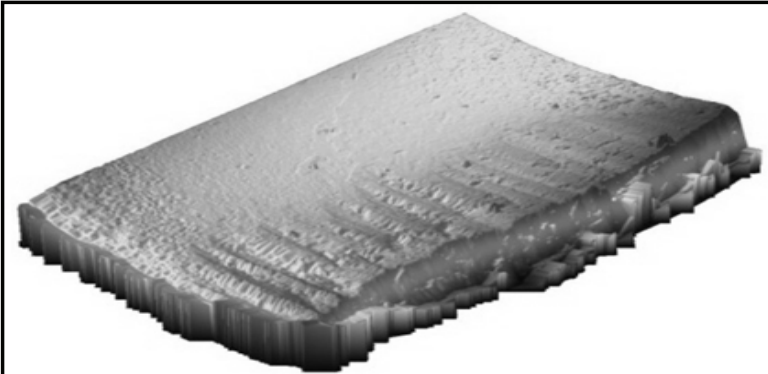

a)

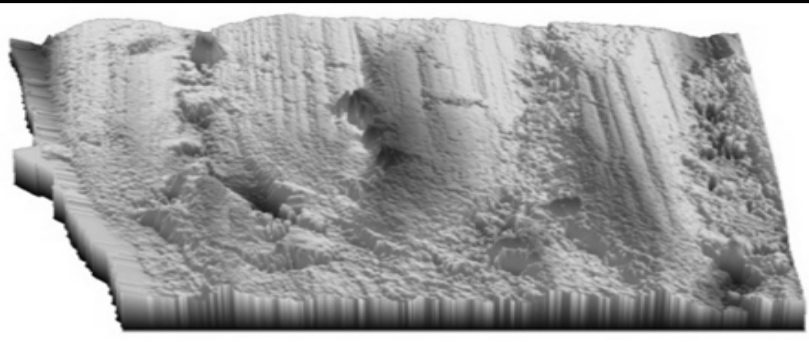

b)

Figure 4: Physical configuration of the contact areas of the coated tool 


\section{CONCLUSION}

The studies helped to develop new designs of PCBN cutting inserts to process the formed components which ensure constancy of the geometrical parameters of the cutting part of the tool in all areas of the grind profile, irrespective of the angle of inclination of the grinded profile of the part. And the radius of the cutting insert and the application of the protective coatings can improve resistance the PCBN tools at the running-on phase by reducing the adhesive interaction between the processed material and tool material.

\section{REFERENCES}

1) Klimenko, S.A., (2011). Processing by cutting processing of details with coatings. Kiev: Institute of Superhard Materials of National Academy of Sciences of Ukraine. (In Ukraine)

2) Mrochek, Zh. A., (2007). Treatment of wearproof coverages. Design ABOUT.

3) Novikov, N.V., Klimenko, S.A., (2006). Superhard materials. The preparation and use 6 units / Under the general editorship. - U. 5. Material Processing by blade tool. Institute of Superhard Materials of National Academy of Sciences of Ukraine. (In Russian)

4) Kogan, B.I., (2013). Progressive cuttings materials for lathe treatment of refurbishable surfaces details of machines. Kuzbas, GTU, 6, 58-65. (In Russian)
5) Mel'nichuk, Yu.A., Petrusha, I.A, Osipov, A.S., (2006). Technological possibilities of blade instrument, equipped diamond-ceramic plates. Technologists of tooling of materials, Kiev, ISM NANU, 51-55. (In Russian)

6) Manovickiy, A.S., (2012). The Cuttings plates from polikristal nitrid of the coniferous forest for the difficult type sharpening of rental rollers. Processes of tooling are in an engineer, 82-87. (In Ukraine)

7) Tabakov, V.P., Chikhranov, A.V., (2007). Wearproof coverages of toolpiece, working in the conditions of the continuous cutting. Ulianovsk. (In Russian)

8) Fomenko, R.N., (2009). Research of wearproof coverages of instrument on the different parameters of cutting process at sharpening. Ufa, T. 12., 4(33), 51-55. (In Russian)

9) Brito, R., Carvalho, S., Marcondes, S., (2009). Thermal analysis in coated cutting tools. International Communications in Heat and Mass Transfer.

Paper sent to revision: 29.12.2016.

Paper ready for publication: 23.08.2017. 